\title{
Can sociologists understand other forms of life?
}

\section{Rachel Cooper}

Lancaster University

\begin{abstract}
Sociologists of Scientific Knowledge sometimes claim to study scientists belonging to other forms of life. This claim causes difficulties, as traditionally Wittgensteinians have taken it to be the case that other forms of life are incomprehensible to us. This paper examines whether, and how, sociologists might gain understanding of another form of life, and whether, and how, this understanding might be passed on to readers. I argue that most techniques proposed for gaining and passing on understanding are inadequate, but I end by describing a method that might work.
\end{abstract}

\section{The problem}

Many workers in Science Studies have been heavily influenced by Wittgenstein's later philosophy. Those influenced by Wittgenstein fall roughly into two groups: "Sociologists of Scientific Knowledge," whose work will be discussed in greater detail in what follows, and "ethnomethodologists," of whom the best known is probably Michael Lynch. ${ }^{1}$ This paper is exclusively concerned with a set of problems faced by the Wittgensteinian Sociologists of Scientific Knowledge. On occasion, these investigators claim to study scientists belonging to other forms of life. For brevity, throughout this paper, I shall refer to people belonging to other forms of life as "aliens"- though it should be borne in mind that I am chiefly concerned

A version of this paper was presented at a seminar in the Department of History and Philosophy of Science, Cambridge University. I have benefited greatly from the comments of those present. Thanks are also due to Harry Collins, Katherine Hawley, Robert Kirk, Martin Kusch, Matthew Ratcliffe, Ken Smith, and to the anonymous referees for Perspectives on Science, who read and commented on drafts of this paper.

1. For discussion of the similarities and differences between these two groups see Lynch (1993).

Perspectives on Science 2004, vol. 12, no. 1

(C) 2004 by The Massachusetts Institute of Technology 
with aliens of the human variety, as opposed to little green men. Claiming to understand aliens causes difficulties. Traditionally, Wittgensteinians have taken it to be the case that alien forms of life are incomprehensible to us (for example, Glock [1996], Kripke [1981]). If this is so, aiming to produce a case study that explains to readers how members of an alien form of life think is doubly problematic. First, on the traditional Wittgensteinian view, sociologists should not themselves be able to understand the aliens. Second, even if by some miracle they do gain understanding, they shouldn't be able to explain what they have learnt to the rest of us.

Some of those who claim to provide case studies examining alternative forms of life are alert to such worries. They accept there are problems with understanding aliens, but hold that these problems can be overcome via the use of "special methods." This paper assesses these special methods. First, I ask whether there are special methods that might enable sociologists to gain understanding of aliens themselves. Second, I ask whether there are special methods that might enable them to pass on this understanding to others. I conclude with both bad news and good news for those who would study others forms of life. On the one hand, most proposed methods for understanding aliens cannot work. Whatever SSK case studies using these methods do, they don't enable us to understand different forms of life. On the other hand, I end by developing an account of a method that I claim might be effective. Projects that require gaining and passing on an understanding of alien forms of life are difficult but not entirely hopeless, I claim.

Debates as to how Wittgenstein's philosophy should be interpreted are fierce and interminable. ${ }^{2}$ Thus, to avoid getting bogged down in questions of exegesis I will merely present the "Wittgensteinian" account prevalent amongst proponents of SSK and leave to one side the question of the extent to which this account actually corresponds to anything held by Wittgenstein. In this paper I am not claiming that "forms of life" should be understood in the "SSK-way." I merely seek to explore the problems with understanding aliens that arise for anyone who does adhere to this conception of "forms of life." As such, if the SSK Wittgensteinian account of forms of life turns out to misinterpret Wittgenstein, or is otherwise mistaken, this is primarily a problem for the SSK Wittgensteinians, not for me.

I will take it that the SSK Wittgensteinian account claims the following:

2. For debate on the correct interpretation of "form of life" see, for example, Finch (1977), Garver (1994), Glock (1996), Hunter (1968). 
1. Members of different forms of life see different similarity relations. They "go on in the same way" differently.

2. We cannot understand beings belonging to a different form of life (at least not without using special techniques).

These claims are made most explicitly in the writings of Harry Collins. In Changing Order, for example, he states that we should "expect groups to be able to communicate readily within themselves because of their members' common ways of going on, but equally we would expect difficulty in communication between culturally diverse groups ... the members of different cultures live within different forms of life" (Collins 1985, p. 15). Martin Kusch and Trevor Pinch, both of whom have written books with Collins, appear to share his views. In The Shape of Actions, Collins and Kusch state that forms of life differ in what is generally accepted as proper ways of going on, and that understanding intentional actions presupposes a shared form of life (Collins and Kusch 1998, pp. 14 and 55). As an understanding of pragmatics requires an understanding of intentions this implies that the language of aliens will make no sense to us. In Frames of Meaning, Collins and Pinch accept that "while the sociologist remains a sociologist he is not a proper native member ... and this may prevent him from understanding native members" (Collins and Pinch 1982, p. 20).

Simon Schaffer and Steven Shapin use Wittgensteinian terminology throughout Leviathan and the Air-Pump, but are somewhat impatient with philosophical discussion. Rather than wanting to discuss whether it is possible to understand their subjects, they just want to get on with the work of doing it (Shapin and Schaffer 1985, p. 15). ${ }^{3}$ Still, several statements made in the book make it clear that Shapin and Schaffer accept that there will be problems with understanding alien forms of life. They say, "it is difficult to see how one could understand a culture to which one was a complete stranger," and "We need to play the stranger, not to be the stranger. A genuine stranger is simply ignorant"(Shapin and Scahffer 1985 , pp. 4 and 6).

Other writers within the SSK movement have been heavily influenced by Wittgenstein, but do not explicitly state that problems with understanding different forms of life should be expected. Barry Barnes has

3. Shapin and Schaffer (1985) p. 15. A similarly pragmatic approach is taken by Collins and Pinch in Frames of Meaning (1982). They say, "How can investigators, let alone readers, understand a self-contained system that is not their own? The answer would seem to be a negative one, but the authors have taken their cue from scientist respondents and got on with the research in a pragmatic frame of mind. As will be seen our claim is that we did achieve this understanding. The reader must find the proof of the pudding, or otherwise, in the eating” (p. 10). 
written a book on Kuhn. He takes "paradigms" and "forms of life" to be equivalent, and states that different forms of scientific life are incommensurable-which strongly suggests that he thinks that different forms of life cannot understand one another (Barnes 1982). David Bloor has written two books on Wittgenstein, but avoids discussing whether problems with understanding can be expected between forms of life (Bloor 1983 and 1997).

As some sociologists of scientific knowledge use Wittgenstein without mentioning problems regarding understanding alien forms of life some readers may wonder whether this paper discusses a problem that exists only in my mind. Maybe when authors talk of "forms of life" this need not be taken to carry the implication that different forms of life will have problems understanding one another? Maybe those authors who do talk of there being problems with understanding have simply made a minor error, and these claims could be deleted from their work without loss. Couldn't the term "form of life" be used to mean simply something like "style of reasoning"? I suggest that this interpretation is not an option, for two reasons. First, many sociologists of scientific knowledge are philosophically sophisticated. They know very well that the term "form of life" is philosophically loaded and that alien forms of life have often been thought incomprehensible. If they wished to use "form of life" without it having this implication surely they would make this clear. Second, studies that have claimed to study other forms of life have drawn conclusions that can only be justified if "form of life" is used in its full-blooded Wittgensteinian sense. Shapin and Schaffer conclude Leviathan and the AirPump by stating "As we come to recognize the conventional and artifactual status of our forms of knowing, we put ourselves in a position to realize that it is ourselves and not reality that is responsible for what we know" (1985 p. 344). Similarly, Collins and Pinch end Frames of Meaning by saying "It would seem that evidence is so bound up with the society or social group which gives rise to it that theories held by members of radically different scientific-social groups cannot be adequately tested against each other by experiment. ... What has been demonstrated, with specific reference to science, is that the idea of paradigm incommensurability, even when interpreted in its most radical Winchian/Wittgensteinian sense, has a part to play in the understanding of contemporary science" (1982, pp. 184-5). When these sociologists of scientific knowledge claim to study alien forms of life, they are talking of "forms of life" in a fullblooded sense, and need to use it in this sense in order to get the conclusions they draw. As such, they invite the question of whether it is possible to understand aliens. 
Characteristically, proponents of SSK give "form of life" a more social reading than would some other Wittgensteinians. They are happy to talk, for example, of Boyle and Hobbes, or of scientists working in Italy and in the U.S., as belonging to different forms of life (Shapin and Schaffer 1985; Collins 1998). As an aside, I shall merely note that whether "form of life" as used by Wittgenstein should be interpreted in such a way is controversial. Some Wittgensteinians would interpret "form of life" in biological rather than in cultural terms, in which case there would be only one human form of life, one Martian form of life, one dog form of life, and so on. ${ }^{4}$ Here, however, for the sake of argument, I shall simply assume that the SSK use of "form of life" is admissible.

Exactly what should count as "gaining understanding of another form of life" is a question that hovers over the entire debate. I suggest that degrees of understanding vary along a continuum. At a very minimal level, some understanding is required for us even to be justified in claiming that the other beings possess a language, as opposed to merely making meaningless sounds. Moving up the scale, we might have understanding sufficient to enable us to make some claims concerning how the other beings see the world, for example we might be able to make statements like "During the Renaissance, people saw the world in terms of analogies." Finally, we might acquire mastery of another form of life, in which case we would be able to pass as native speakers.

The extent to which sociologists of scientific knowledge need their readers to gain understanding of an alien form of life depends on the details of their project. In some cases it might be enough for readers to simply come to know that other reasonable people have thought about evidence, experiment, or whatever it might be, differently. At least in some cases, however, sociologists of scientific knowledge have engaged in projects that require readers to gain a far higher degree of understanding. Shapin and Schaffer's Leviathan and the Air-Pump opens with a quote from Umberto Eco's The Name of the Rose. According to the quote, God understands the world because "He conceived it in His mind, as if from the outside." Shapin and Schaffer likewise wish to shed light on the experimental form of life by presenting a view of it from the outside. They seek to do this via coming to share the point of view of Hobbes, who in their view was an outsider to the experimental form of life. They say, "We shall be adopting something close to a 'members account' of Hobbes's antiexperimentalism. That is to say, we want to put ourselves in a position where objections to the experimental programme seem plausible, sensible 
and rational" (Shapin and Schaffer 1985, p. 13.). For such a project, knowing that Hobbes was a clever man, and that he probably had his reasons for thinking what he did, will not do. Rather the aim is to at least begin to think like Hobbes.

Shapin and Schaffer's ultimate aim in adopting Hobbes' ways of thinking is to make our own practices seem strange. They seek to temporarily alienate us from our own form of life. With this goal in mind, it might be thought that whether they succeed in accurately depicting the actual alien form of life inhabited by Hobbes, or just manage to sketch a possible alternative form of life, doesn't much matter. For their project they only need to show us that our ways of thinking are not the only possible ones. This line of thought might be taken to suggest that my worry about whether we can gain understanding of aliens is misplaced. So long as Leviathan and the Air-Pump succeeds in problematizing the practices of experimentation, through showing that it would be possible to think otherwise, who cares whether the portrayal of Hobbes is accurate or not?

I suggest that this line of thought is mistaken. If Leviathan and the Air-Pump succeeds in showing that an anti-experimental form of life is genuinely possible, it does so through showing that an actual person, Hobbes, was a member of such a form of life. It is because Shapin and Schaffer claim to have evidence that a sane and clever man managed to live a consistent anti-experimentalism, that they can claim that such an approach is a coherent possibility. That SSK descriptions of other forms of life need to be accurate to achieve their authors' aims is brought out more clearly in the work of Harry Collins. Collins sees his case studies as contributing to an "empirical relativist programme" (Collins 1983). ${ }^{5}$ His case studies are supposed to provide empirical evidence that supports relativist claims. The case studies can only do this if they are accurate. Collins' concern that other researchers should be able to replicate his findings further illustrates that he intends his descriptions of alien forms of life to accurately convey actual ways of thinking (Collins [1983], pp. 92-93; [1984], p. 65.)

In the remainder of the paper I examine the techniques that are candidate methods for enabling us to understand alien forms of life. First, I ask how sociologists might gain understanding of alien forms of life themselves. Second, I ask how this knowledge can be passed on to readers. The issues involved in asking whether we can understand beings belonging to different forms of life are closely tied to those involved in asking whether understanding is possible across Quine's conceptual schemes or Kuhn's

5. The idea that SSK case studies provide empirical support for relativism also comes over clearly in Barnes and Bloor (1982) p. 24. 
paradigms. ${ }^{6}$ Because these issues are so closely linked, and the literature specifically on understanding different forms of life is sparse, I shall make use of arguments that were originally intended as contributions to these other radical interpretation debates within this discussion.

The discussion here, concerned with the claims of Wittgensteinian Sociologists of Scientific Knowledge to understand alien forms of life, also has links with debates in anthropology concerning problems with understanding radically different cultures, and debates in historiography concerning problems with understanding people from different historical periods. Although much of the discussion here will be relevant to these other debates, I concentrate specifically on the problems faced by Wittgensteinian Sociologists of Scientific Knowledge. This is because problems with understanding the other take on different forms depending on the theoretical commitments of the theorists involved. I concentrate on the problems faced by Wittgensteinian Sociologists of Scientific Knowledge because the problems faced by this group are of direct interest to science studies. In addition, members of this group explicitly share a set of theoretical commitments, in a way that, say, anthropologists, do not, making the difficulties faced by Wittgensteinian Sociologists of Scientific Knowledge more accessible to philosophical analysis.

\section{How to understand aliens}

\section{Candidate method 1. Translation}

Many of the sociologists of scientific knowledge hold that translation between forms of life is impossible. ${ }^{7}$ I agree with them. However, translation remains the most obvious way in which we might attempt to gain understanding of another form of life, and so the reasons why it will not work are worth reviewing.

In "The very idea of a conceptual scheme," Davidson famously argued that the project of trying to translate from another conceptual scheme into our own is incoherent. Davidson goes on to claim, as a result, that individuation criteria for conceptual schemes are lacking, and thus that talk of "conceptual schemes" is nonsensical. Although Davidson is concerned with Quinian conceptual schemes rather than with Wittgensteinian forms

6. There are important differences between the debates. Quine (1960) thinks that there are multiple translations between conceptual schemes, while Kuhn (1962) thinks there is no way to translate between paradigms, but these differences need not concern us here.

7. See Collins (1985) p. 25, note 14. Barnes (โ1982], p. 68) writes, "there are very strong grounds for holding that translation of this kind is not possible." (Barnes is discussing translation between paradigms, but uses "paradigm" and "form of life" interchangeably.) 
of life, his argument that translation between conceptual schemes is impossible can also be used to argue against the possibility of being able to translate from one form of life to another.

Davidson claims that whenever we are faced with a being making a nonsensical sentence we have a choice. We can either translate the sentence in such a way that the being appears to share our concepts but has false beliefs, or we can translate the sentence in such a way that the being appears to have true beliefs but different concepts. There is nothing to choose between the two options. If we translate the sentence in such a way that the being has different concepts then they will count as a member of another form of life. But, as we could just have easily have taken the alternative translation, it makes no sense to claim that the being actually either is or is not a member of a different form of life. To use Davidson's example, suppose a person says, "Look at that handsome yawl!" as a ketch is sailing by. When attempting to make sense of this statement we can either suppose that the person is using the word "yawl" to express a different concept from ourselves, and thus maybe sees the world differently from the way we see it, or we can suppose that the person simply has a false belief about the sailing boat-they mistakenly think it is a yawl. No evidence can enable us to decide which of these options we should take. To take another example, this time from the history of science, one seventeenth century "refutation" of Galileo's discovery of the moons of Jupiter argued that as there are seven "windows" of the head there must also be seven planets. ${ }^{8}$ Either we can conclude that people in the seventeenth century thought in a radically different way to ourselves, or we can make sense of the argument by positing that they had the false belief that God created harmony between man and the heavens.

H. J. Glock has suggested that Davidson's claim, that the alien speech cannot be translated, might be resisted by thinking of translation as being achieved on the basis of similar patterns of behavior, rather than as depending on shared beliefs (Glock 1998). The thought seems to be that an alien word should be translated as, say, "salt," not because the aliens share our beliefs that the stuff is sodium chloride, that there is lots of it in the sea and so on, but because everyone scatters it over their fish and chips. This idea is incoherent. Another's beliefs and another's behavior should not be considered as independent criteria for establishing a translation. As we are not telepathic, we only have access to other's beliefs via their behavior, and we attribute to others those beliefs required to rationalize their behavior. Thus if a being presents us with behavior that is similar to our own (which might well include verbal behavior such as saying "I believe

8. Attributed to Francesco Sizi, cited in G. Holton and D. Roller (1958) p. 160. 
salt is sodium chloride") we conclude that the being possesses the same beliefs as us. Appeals to behavior do not offer a way out, and we can conclude that we will be unable to directly translate between forms of life.

I accept Davidson's argument that it is not possible to translate between conceptual schemes, or forms of life. However, I do not accept that this demonstrates that talk of conceptual schemes or forms of life is incoherent. Davidson's argument depends on the assumption that the only way we could gain understanding of aliens is via translation. Having dismissed the possibility of translation, Davidson concludes that we could not gain understanding of an alien conceptual scheme, and thus that talk of conceptual schemes is nonsensical. I think that it is possible to gain understanding of aliens, though not via translation, and thus resist Davidson's conclusion that talk of conceptual schemes, or forms of life, is incoherent.

It is worth noting that even if translation could be achieved, there is reason to doubt that this would necessarily be sufficient for understanding. In the Philosophical Investigations, Wittgenstein briefly raises the possibility that we could come across a strange people who use the same words as us, but still not be able to understand them. It might be that although their words made sense to us, their sentences did not. We would not be able to "find our feet" with such a people (Wittgenstein 1958, p. 223). Indeed such cases seem fairly commonplace. Consider, the following example given by Martin Hollis (1996, p. 199). Hollis reports that some Yoruba people carefully carry boxes covered with cowrie shells wherever they go. When asked about the boxes they reply that they are their heads or souls and must be protected from witchcraft. In this case the words make sense, but I suggest that the statement is incomprehensible to us. We cannot make sense of what it would be like to live as someone who believed that a box was his or her soul. I conclude that translation between forms of life cannot be achieved, and in any case might well not be sufficient for understanding.

Candidate method 2. Overlapping Forms of Life

Two forms of life overlap, but are non-identical, when their members see the same similarity relations and "go on" in the same ways in some, but not all, domains. Sometimes it is suggested that when forms of life overlap a sociologist can make use of the shared portion in order to explain the unshared portion. ${ }^{9}$ While he was not explicitly talking about forms of life, something like this idea has been articulated in greatest detail by Martin

9. Suggested as a way of translating between Kuhnian paradigms by Kindi (1995) p. 89. 
Hollis. In a series of papers Hollis has claimed that alien cultures can always be interpreted, as any two cultures will necessarily share a "bridgehead" of universally shared beliefs ( $\{1967 \mathrm{a}, \mathrm{b}\rfloor 1970,1982)$. According to Hollis the bridgehead consists of "what a rational man cannot fail to believe in simple perceptual situations, organized by rules of coherent judgement, which a rational man cannot fail to subscribe to" (1982, p. 74). The investigator is supposed to build on these shared basic beliefs and practices to gain understanding of beliefs and practices that are not shared.

Hollis' claim that there is a core set of beliefs and practices shared by all cultures is dubious. As Barnes and Bloor point out, the doctrine of the bridgehead seems to be a version of the idea that there is a pure observation language (referring to "what a man cannot fail to perceive in simple perceptual situations"), that can be contrasted with language that is more theoretical and problematic (1982, pp. 39-40). The notion that a distinction can be drawn between an observational and a theoretical language has been widely rejected (see, for example, Churchland [1988], Kuhn [1962], Popper [1959]). Barnes and Bloor nicely bring out some of the difficulties through showing how even a paradigmatically empirical term such as "bird" can be problematic. They report that the Karam of New Guinea have a term "yakt" that refers to most birds, and also bats, but excludes cassowaries. The resulting class seems natural to the Karam, who see all "yakt" as being alike. We, however, do not see the similarity relations that they do, and so find the class unnatural. An anthropologist who took it that the Karam must see similarities where we do would be led badly astray.

Following Barnes and Bloor, I suggest that Hollis is wrong to claim that aliens will necessarily see things roughly as we do. The existence of a universally shared "bridgehead" can be doubted. In addition, and more importantly, even in cases where there is some "bridgehead," and forms of life do have some overlap, this overlap cannot be used by an investigator to gain understanding of the alien portion of a form of life. Members of a form of life see the same similarity relations and find it natural to "go on" in the same ways. However, they cannot explain to a partial outsider why it is that certain things seem obvious and natural to them. This is because they have no explanation for why it is that they "go on" in the way that they do - the way that they do things simply strikes them as the only possible way of doing things. Consider Wittgenstein's example of the odd adder (Wittgenstein [1958], §185). The odd adder is assumed to speak English. To some extent he is like us. Still, it is impossible for us to explain to the odd adder why we produce the sequence $2,4,6,8,10, \ldots$ from the rule "add two." We find it natural to apply the rule in this way, the odd 
adder finds it natural to do otherwise, and that it all there is to be said. As members of a form of life cannot explain the practices that make up their form of life to themselves, they haven't got a hope of being able to explain them to a member of an overlapping form of life.

A real life example from Oliver Sacks The Anthropologist from Mars further illustrates the limits of our explanatory powers. Sacks describes a highly intelligent autistic person who is perfectly capable of understanding advanced scientific literature (Sacks [1995], "An Anthropologist on Mars"). Nevertheless, despite repeated attempts at explanation, they cannot grasp the concept of having a friend. Similarly, it is not possible to explain to a profoundly deaf person what it is like to hear. Even when beings belong to overlapping forms of life, they cannot use what they have in common to explain their differences.

Candidate method 3. Anthropological methods

Many authors have suggested that "anthropological" methods can be used to gain understanding of alien forms of life (for example, Collins [1998]; Barnes and Bloor [1982], p. 37; Feyerabend [1987], p. 76; Kuhn [1982], p. 673). The idea seems to be that by immersing oneself in another culture, perhaps for several years, one can learn to perceive the world as members of another form of life perceive it.

The anthropological method is different from the overlapping forms of life method discussed in the last section. In the overlapping forms of life method, the sociologists go up to an alien, whose form of life overlaps with their own to some extent, and ask the alien to explain those practices that seem odd. As discussed, this method fails because there are no such explanations. In contrast, someone using the anthropological method does not seek understanding primarily through explanation. Rather, they seek to learn the alien form of life as does an alien infant-through "immersion" in the culture, or "socialization." 10 While it's unclear exactly how infants learn to behave appropriately, it is certainly the case that at least to begin with they do not rely on language. To some extent, infants, and anthropologists, are trained using the same methods that are used to train animals (although this will not be the whole story). Their behavior is modified by the use of rewards and punishments, and adult aliens use a variety of strategies to manipulate them into behaving well (for example, they can make sure they are hungry at appropriate times by regulating their access to food). Anthropologists will learn a form of life to a large

10. For discussion of the anthropological method of participant observation aimed at anthropology students see Bernard (1988). 
extent through conditioning, and also through trial and error. To put things crudely, rather than having things explained to them, they will learn at least the basics through being bashed into shape.

The first thing to be said about the anthropological method is that even if it would work the anthropological approach would be limited in its application. Learning a new form of life through enculturation would require that the anthropologists enter into social interactions with their subjects. This leaves much of the historical side of SSK in difficulties, to put it mildly. ${ }^{11}$ It is clearly impossible to interact socially with dead subjects. Historians might attempt to become enculturated by, for example, visiting places where their subjects lived, using the instruments they used, and trying to live as they did. However, the information that can be gleaned through such practices will still radically underdetermine the form of life of the subjects. Historians should not be fooled into thinking that they can make plausible attempts to fill in the gaps in their knowledge via trying to empathize with the people they are studying. Different forms of life differ as to what seems natural. Thus we have every reason to think that historians' judgements of "what must have been the case" will not correspond to how their subjects would have seen things.

The claim that historians cannot gain understanding of dead people who thought very differently is not novel, but has a respectable pedigree. R. G. Collingwood held that for historians to gain understanding of their subjects it is necessary for them to re-enact their subjects' thoughts. This would not always be possible. For re-enactment, "The object must be of such a kind that it can revive itself in the historian's mind; the historian's mind must be such as to offer a home for that revival" (Collingwood 1961, p. 304). In cases where historians are very different from their subjects, their minds might be incapable of rethinking their subjects' thoughts, and they will not be able to understand them.

Historians cannot use the "anthropological method," but might sociologists have more luck? Might it be possible for sociologists to become a member of two or more forms of life by immersing themselves in different cultures? Robert Kirk has argued that it is impossible that someone could gain simultaneous mastery of two forms of life. Suppose someone had mastery of two forms of life then, he writes, “ . . someone whose natural predispositions and tendencies allowed them to speak one of the languages in a way acceptable to native speakers could also possess natural predispositions and tendencies which enabled them to speak the other equally acceptably. But this would be possible only if the same set of natural dispo-

11. Collins (1981) makes similar claims. 
sitions enabled someone to speak both. And that is impossible. For the point about forms of life is that given our predispositions, we agree on what is acceptable, while anyone with a different set of predispositions would not agree with us. Having both sets would involve having incompatible predispositions" (1986, p. 214).

Unlike the writers I have discussed so far, Kirk considers forms of life to be largely biologically grounded (Kirk [1986], p. 23). When he talks of "predispositions" he thinks of these as being biologically fixed. The reason why it is impossible to possess two sets of such predispositions at once is that our brains must either be "set" in one way or another.

While, as mentioned earlier, the interpretation of Wittgenstein's "forms of life" is controversial, Kirk must be right in thinking that at least one sense in which it is intended is biological. "If a lion could talk, we could not understand him" (Wittgenstein [1958], p. 223), and this, it is implied, is because the lion belongs to a biologically different form of life than ourselves. Furthermore, Kirk must also be right in thinking that some ways of life are inaccessible to us for biological reasons. Our sense organs and brains are such that what it is like to be a bat, for example, will famously always be hidden from us.

Even if we restrict ourselves to the sense of "form of life" used in the rest of this paper, and think of people from different cultures as belonging to different forms of life, there may be cases where it is impossible to learn a form of life because our brains lack the requisite flexibility. Proponents of the method of enculturation are fond of pointing out that babies learn the form of life into which they are born with few problems (see for example, Barnes and Bloor [1982], p. 37; Collins [1985], p. 25, note 14; Feyerabend [1987], p. 76). The moral they wish us to draw is that total immersion in a culture will enable them to learn ways of going on with comparable ease. While the successes of anthropological fieldwork demonstrates that it is often possible for an investigator to come to think in new ways, it may not be the case that an adult investigator can learn anything that a native infant can. There may be a crucial period of time in which an infant is biologically primed to learn "ways of going on." Eric Lenneberg, and other adherents of the Critical Period Hypothesis, claim that humans are biologically predisposed to learn languages with ease only during a period lasting from the age of about two to the early teens (Lenneberg 1967). Learning a form of life might well be similar. If this were the case, anyone who seeks to learn a form of life outside of this critical period may encounter great difficulties. Indeed, anecdotal evidence suggests that this may well be the case. The children of immigrants are often able to "go native" while their parents are not. Both may be totally immersed in an 
alien culture, but younger brains can absorb it in a way that older brains cannot.

Here I have stressed that there may well be biological limits to the forms of life that we can learn because I think this is a point that has often been ignored by those who would learn to think like aliens. The assumption that a middle-aged academic can easily learn anything that an infant can learn is optimistic, to say the least. This being said, in the sense in which the Sociologists of Scientific Knowledge use "form of life," there will surely be cases where differences between forms of life are founded on differences in mental software as opposed to differences in brain hardwear. The differences between Italian and American physicists, for example, are unlikely to lead to unalterable biological differences in their brains. When differences between forms of life are not biologically fixed, it may be possible for a person to possess two separate sets of dispositions, and thus to belong to two forms of life at once. A range of commonplace phenomenon suggests that this can happen. Different sets of dispositions may be activated depending on the social context. Many people, for example, find that different accents and different vocabularies come naturally to them in different social settings. Thus a person can find it natural to speak perfect B.B.C. English when giving a presentation, but revert to something quite different in the pub. Similarly we could imagine someone who found it natural to think in accord with different forms of life depending on the environment. And indeed, this is how those who claim to be familiar with two forms of life suggest it works. In their study of parapsychology, Collins and Pinch found that their beliefs "tended to change as a function of the nature of the latest period of prolonged exposure to scientists," that is when with parapsychologists they found it natural to think like parapsychologists, and when with doubters they found it natural to think like doubters (Collins and Pinch [1979], p. 715; Collins and Pinch [1982], p. 23).

Thus, while in certain cases our biology may render us incapable of assimilating a form of life, plausibly there will be other cases where this is not a problem, and I am happy to accept the possibility that one might come to be a member of two distinct forms of life through enculturation (at least in the sense of "form of life" whereby people from different cultures belong to different forms of life). Let's suppose, then, that our anthropologists succeed in understanding the native form of life. Still, their task is not complete. In order for the anthropologists to be academics rather than people who have just "gone native," when they eventually return to their home culture they must be able to pass on some of the understanding they have gained. This leads us to our second question, once the 
anthropologists have come to understand the aliens, can they pass on what they have learnt to their readers?

\section{How to pass on understanding of aliens}

I have come across three suggestions as to how anthropologists might be able to pass on what they learn to their audience. Two are unsatisfactory; the third can be developed into an account of a method that might work.

Candidate method 1. Translation

As already discussed, straight translation between two forms of life is impossible. Still, the thought might linger that a bilingual would be able to achieve a translation where others could not. This is a mistake. The fact that in the person of the anthropologist one individual has mastery of two forms of life is not going to help matters. Quine best puts the point. He asks us to imagine a bilingual engaged in the construction of a translation manual from Jungle to English. The bilingual will have to set about his task "much as if his English personality were the linguist and his jungle personality the informant; the differences are just that he can introspect his experiments instead of staging them" (Quine 1960, p. 71). Thus the anthropologist who attempts to translate from one language to the other will succumb to the problems discussed in the last section.

Candidate method 2. Evolving and merging forms of life

Another suggestion is for the returning anthropologists to try to make use of the possibility that forms of life can evolve and merge into one another. ${ }^{12}$ Perhaps the returning anthropologists could so act on their native form of life that it evolved to the extent that it merged with the alien form of life, enabling the anthropologists' knowledge to be understood. There are two problems with this idea. The first problem is that changing a form of life is not easy. Even on the liberal reading of "form of life" favored by the proponents of SSK, a form of life is constituted by deep seated habits of reasoning, customs, ways of seeing the world, and so on. Although it is not clear exactly what it would take to change these, it is likely that it would be a difficult and time-consuming business. If the anthropologists just write a handful of papers and give a few seminars this probably will not be enough to do the trick. The second problem is that even if the an-

12. Suggested in the context of Kuhnian paradigms by Kindi (1995). Winch ([1964] 1970) suggests that "seriously to study another way of life is necessarily to seek to extend the boundaries of our own-not simply to bring the other way within the already existing boundaries of our own, because the point about the latter in their present form, is that they ex hypothesi exclude the other"(p. 99). 
thropologists are influential enough to change the form of life, the way in which it will change will not be under their control. Wittgensteinian relativists claim that what seems rational, and what is true, depends on our form of life. However, although truth is in some sense a human construction, they constantly stress that this does not mean that we can change the truth to fit our desires. Thus the anthropologists cannot set out to alter their form of life in such a way that it merges with an alien form of life.

Candidate method 3. Employing the "Techniques of the novelist"

Harry Collins suggests that anthropologists can relay knowledge of the other form of life using the "techniques of a novelist" (Collins [1984]; Feyerabend [1987] makes a similar suggestion). However, this is a suggestion he does not expand on in any detail. Discussing how, and what, we can learn from novels is a slippery business, and so developing Collins' suggestion, and then assessing it, will take some time. The effort, however, will be worthwhile. I shall argue that Collins' suggestion can be developed into a method that might, in some cases, enable readers to gain understanding of an alien form of life. Although Collins suggests that using the techniques of the novelist may help, the development of this idea given here is my own. Whether Collins would approve of it or not, I'm not sure.

The idea that using the "techniques of the novelist" might help is best approached via a consideration of tacit knowledge. Tacit knowledge, we all know, cannot be learnt via reading normal instructions. Still tacit knowledge can be learnt, and the process via which it is learnt cannot be purely mysterious. Maybe scientists can't get the equipment to work merely by reading the instructions manual, but if they spend long enough working with people who already have the necessary expertise they should eventually pick up the required skills.

This transfer of knowledge does not involve telepathy. Novices who eventually gain expertise must be picking up observable information from the environment. Admittedly, this will not be limited simply to what they are told. Body language may be important. Having the opportunity to observe exactly what the other scientists are doing, and to copy them, and be corrected by them, may be necessary. Still, when novices develop into experts the information they are picking up on must be made manifest in some way. Something about what they can see, or hear, or feel, gives them the information that they need.

In some cases it is possible to recreate those aspects of the environment that learners pick up on, and thus to train novices in artificial environments. For example, flying a plane must be an activity that requires tacit knowledge, if any does, and novice pilots are trained in part on flight sim- 
ulators. Flight simulators do not simulate aeroplanes in all respects, but are similar enough in relevant respects to enable pilots to learn to fly. In such cases, tacit knowledge can be learnt in a virtual environment.

Jane Heal suggests that Wittgenstein should be interpreted as claiming that understanding can best be thought of as an ability (Heal 1998). Such a model implies that learning to understand beings belonging to an alien form of life and learning tacit knowledge will be similar enterprises. As such, if tacit knowledge can sometimes be learnt through interacting with virtual environments, it may be possible to learn a form of life in a similar way. This, I take it, is where the notion of using the "techniques of the novelist" comes in. In a sense, a good novel transports the reader into a virtual world. ${ }^{13}$ A well-described scene becomes vivid in our mind's eye, and we react to the characters of the fiction in many respects as we do to real people. Although Collins does not flesh out his suggestion in any detail, I take it that the anthropologists aim would be to use the techniques of the novelist to transport their readers into an imaginary environment that models the environment in which the anthropologists have done their fieldwork. The anthropologists gained understanding of an alien form of life via immersion in a real alien environment. The hope is that the reader will be able to gain some understanding of that form of life through immersion in an imaginary alien environment. It will be useful to have a term for the texts that might facilitate such an immersion. I will call them anthro-novels.

What are the techniques that the writers of anthro-novels might use in order to help their readers vividly imagine aliens? In Leviathan and the Air-Pump, Shapin and Schaffer claim that Robert Boyle used literary techniques in order to enable the readers of his experimental reports to virtually witness the experiment by reproducing it in their imagination (as air-pumps were rare and expensive, a virtual air-pump was the best that most of his readers could hope for). The task faced by the writer of an anthro-novel is somewhat similar to that faced by Boyle, and the same kinds of methods might be used. Boyle provided his readers with pictures of his air-pumps. "By virtue of the density of circumstantial detail that could be conveyed through the engraver's laying of lines, they imitated reality and gave the viewer a vivid impression of the experimental scene" (Shapin and Schaffer 1985, p. 62). Boyle also described his experiments at length and gave many circumstantial details. Shapin and Schaffer report that even Boyle's sentence structure "with appositive clauses piled on top of each other, was ... part of a plan to convey circumstantial details and to give the impression of verisimilitude" (Shapin and Schaffer 1985, p. 63).

13. I am grateful to Ken Smith for suggesting this idea to me. 
Writers of anthro-novels might learn from Boyle and seek to make their descriptions vivid through providing pictures and details. Other techniques might also be employed. Collins has tried including quotes from interviews in his work, in an attempt to mimic the effect of dialogue in novels. ${ }^{14}$

Unfortunately, however, there are reasons for thinking that simply describing the alien environment, however vividly, will not be enough. The anthropologists did not learn the alien form of life simply through observation, but via interaction. They made mistakes, and were corrected, and gradually came to be able to do the right thing. If the reader's immersion in an imaginary environment is to function like the anthropologists' immersion in a real environment, then the process the reader goes through will probably need to be something like the process the anthropologists went through. And here a problem emerges: It is impossible for a reader to interact with imaginary alien characters. Their lines have already been written, and so they can't respond to the reader's questions or comments. Admittedly, when reading normal novels a reader might gain some understanding of characters by engaging in imaginary dialogue with them. In the case of alien characters, however, such methods will not work. If a reader tries to imagine how an alien character would respond to a question, the answer they generate will almost certainly be way off the mark. The character, after all, is alien, and so they will not respond as the reader would think natural.

The only way around such problems that I can think of is for there to be a character in the anthro-novel with whom the reader can empathize. A character belonging to the same form of life as the reader, who will ask the alien characters the questions the reader would ask, and will respond to their oddities as the reader would. The easiest way of achieving this would be if the anthropologist featured as a character. The anthro-novel would recount the anthropologist's interactions with the aliens. Through empathizing with the anthropologist, the reader would become immersed virtually in the alien-culture, and this immersion would enable the reader to learn to understand the alien culture, in the same kind of way as the anthropologist's actual immersion enabled the development of understanding. Or, that at least would be the hope.

In some cases anthro-novels would not work. I suspect that a form of life may be under-pinned by physical factors that cannot be reproduced via reading a novel. Aliens may think in the way they do because they are drunk, or high, or hungry, and in such cases I doubt that it will be possi-

14. See Collins and Pinch (1982) for examples. In personal correspondence Collins has told me that the point of these interview quotes is to mimic a novel. 
ble for the reader of a novel to come to reproduce their ways of thinking unless they happen to have been in the same kind of state. Some are more optimistic about the abilities of novelists than I am, and think it relatively unproblematic for a novel to convey what it is like to be insane, or on drugs, for example. I accept that I may have been overly impressed by the claim traditionally made by philosophers of mind that what it is like to experience particular "qualia" or "raw feels" cannot be conveyed in words (see, for example, Jackson [1986], Nagel [1974]). Although such claims are often made, it is true that they tend to be accepted as intuitively obvious, rather than argued for. I have no way of convincing those who do not share such intuitions that they are correct. I can only say that other philosophers than myself have found it intuitively plausible that words cannot convey what it is like to experience qualia (although if pushed I would be forced to accept that this may just indicate that we lack imagination).

Even where such potential problems are not a worry, an anthro-novel would demand a lot from the reader. The reader must become immersed in an imaginary environment in a way that mimics the anthropologist's immersion in a real environment. Immersion in a culture takes time and active participation. As such, anthro-novels would probably have to be quite long, and the reader would have to actively empathize with the character of the anthropologist. Readers who skimmed pages would be unlikely to achieve the necessary level of involvement.

Writers of anthro-novels will also have a tough job. Writing novels is not easy, and sociologists of scientific knowledge who wished to use such a method would have to learn new skills. Interestingly, however, the writers of anthro-novels will not have to worry about one traditional constraint on case studies in the social sciences. The account of interactions with the aliens does not have to be literally true. The point of the anthro-novel is not to tell readers what happened, but to enable them to come to understand alien ways of thinking. As such, dialogue does not have to record word for word what the aliens actually said; reproducing the kinds of things they would say if asked particular questions will do. Indeed, in some cases the writers of anthro-novels might best help their readers to virtually experience what they experienced in real life by not telling the literal truth. Plausibly, seeing things in the mind's eye has a different effect than really seeing them. In many cases actually seeing something is more vivid than just imagining it. In such cases a scene in an anthro-novel might have to describe things in unrealistically extreme terms in order for the effect on the reader to be analogous to the effect of the real scene on the anthropologists. In other cases, the effect of reading about something might be more vivid than experiencing it in real life. Reading about 
something takes a minimum amount of time, while in reality even extreme thoughts or feelings can be fleeting and so have little effect. In such cases, authors might have to tone down a report of what they actually experienced if the effect on the reader is to be similar.

So far as I know, no Sociologist of Scientific Knowledge has written anything resembling an anthro-novel. However, books very like the anthro-novels I have described exist in other fields. An example is Elenore Smith Bowen's Return to Laughter, which is a fictionalized account of Bowen's experiences of fieldwork with an African tribe. Bowen's primary aim is to convey what it is like to experience the tensions of fieldwork. She seeks to convey what it is like to be an anthropologist being changed by immersion in an alien culture, and focuses in particular on the personal and moral problems that are caused by living between two cultures. As Bowen aims primarily to convey what it is like to be an anthropologist, rather than to enable the reader to come to understand the African tribe with whom she lived, Return to Laughter differs somewhat from my idea of an anthro-novel. Bowen spends more time describing her own feelings, and less time discussing the reactions and customs of the tribe than would an anthro-novel that aimed to convey understanding of an alien culture. Still, Return to Laughter gives quite a good indication of what an anthronovel would be like, in that it is a fictionalized account that succeeds in getting the reader to empathize with the character of the anthropologist.

Where differences between forms of life are not physically grounded, and an anthro-novel is well-written, and the reader actively empathizes with the character of the anthropologist, an anthro-novel might enable readers to gain some understanding of an alien form of life. Some will find the "might" in the last sentence pathetically non-committal, but it is, I think, unavoidable. On the one hand there are good reasons to think that tacit knowledge, and understanding of a form of life, cannot be passed on via normal texts. On the other hand, the process via which such knowledge is passed on cannot be magical. As such, it should be possible to learn anything that can be learnt via immersion in a real environment through immersion in an artificial environment-providing the necessary features of the real environment have been replicated. Whether the imaginary environment created by an anthro-novel would be a good enough replication to enable the reader to gain understanding of an alien form of life is, I think, an empirical question.

That a reader felt they had gained understanding of aliens would of course not be sufficient to demonstrate that the anthro-novel had actually been successful-it's a sad fact of life that we often think we have understood things that we have not. This is why we usually require people to 
prove their understanding via some kind of performance. Students may sincerely think they have understood formal logic, say, but their claims are so unreliable that we commonly place no weight on them at all. Only a student who can actually construct truth tables, and translate into propositional logic, is accredited with understanding.

Similarly the understanding of the reader of an anthro-novel must be judged by what they can do. The ultimate proof that an anthro-novel can convey understanding would be if someone who read the novel could acquire skills that can normally only be learnt through enculturation. The most straightforward case would be if someone who had read the book could pass as native in the alien culture. Almost certainly, however, this is an unrealistic goal. A reader who could pass this test would have come to see the world at least largely as the aliens see it - a task that might have taken the anthropologist several years. Still, a reader could convey that they had grasped at least some of the alien "ways of going on" if they could predict how an alien would react in some novel circumstances. If one has understood the differences in the evidential cultures of Italian and American physicists, for example, one should have some idea which group will be most likely to consider a new experiment as providing evidence for a particular hypothesis.

I have claimed that historians of science cannot learn an alien form of life through enculturation because their subjects are dead. However, in some cases the analysis of controversies in the history of science might enable historians to gain understanding of aliens in somewhat the same way that I am suggesting anthro-novels might enable readers to gain understanding of aliens. Suppose one historical actor, Mr. Similar, is involved in a debate with another historical actor, Ms. Different. Mr. Similar happens to think in a way rather like ourselves; Ms. Different is an alien. Mr. Similar's reports of his confrontations with Ms. Different might function for the historian like an anthro-novel written by an anthropologist. Mr. Similar can interact with Ms. Different and so gain some understanding of her ways of thinking. At the same time Mr. Similar is sufficiently like us for us to be able to empathize with him. Through reading Mr. Similar's reports of his arguments with Ms. Different, and empathizing with Mr. Similar, the historian might be able to virtually interact with Ms. Different and so come to gain some understanding of the alien form of life.

In general, however, there are reasons to be pessimistic about such an approach. Coming to understand a form of life through immersion in a real culture is quite difficult. Coming to understand a form of life through reading an anthro-novel would be harder. Coming to understand a form of life through reading notes on a historical controversy would be harder yet. This is because anthro-novels would be specifically written with the inten- 
tion of facilitating immersion in an imaginary world - they would be designed to contain all the information the reader would need. In contrast, historical records are likely to be patchy and were never written with the intention of facilitating virtual interaction with aliens.

\section{Conclusions}

If the arguments of this paper are correct, then it contains both bad news and good news for those who aim to understand aliens.

The good news

I have argued that there is a method that might enable sociologists of scientific knowledge to gain understanding of an alien form of life and to pass on this understanding to their readers. The sociologists would first have to gain understanding of the form of life themselves through enculturation. It should be noted that in some cases biological differences between members of different forms of life would make this impossible.

If the sociologists of science succeed in becoming enculturated then their next challenge is to create an anthro-novel. The anthro-novel will recount their interactions with the aliens. If all goes well, through empathizing with the anthropologists, the reader will become immersed virtually in the alien-culture, and this immersion will enable the reader to learn to understand the alien culture, in the same kind of way as the anthropologists' actual immersion enabled them to develop understanding.

While I hold that anthro-novels offer the best hope for the sociologist of scientific knowledge who is trying to pass on understanding of an alien form of life, I have not argued that they will definitely work. Whether the virtual environment created by an anthro-novel would be good enough for immersion in it to be relevantly equivalent to immersion in a real environment is, I think, an empirical question.

The bad news

The bad news is that so far as I know no Sociologist of Scientific Knowledge has written an anthro-novel to date. As such those existing case studies that claim to enable readers to understand scientists belonging to different forms of life cannot be doing this. The techniques that their authors use to try and enable the aliens to be understood are simply not up to the job.

Of course this does not mean that I think that nothing can be gained from current historical or sociological case studies. Although for ease of discussion I have spoken about forms of life as if they were discrete, it is probably better to think of forms of life as hierarchical and messy. Thus two actors could share a form of life at one level, for example they could 
both be human, but belong to different forms of life at a finer discrimination, for example one could be an Ancient Greek while the other comes from twenty-first century London. All the points made earlier still stand. In the absence of enculturation (either obtained via fieldwork or an anthro-novel), I claim that one actor can understand the other only in so far as they already share a form of life. Thus we can understand the Ancient Greeks to a certain extent because we share a form of life at one level, but in so far as we belong to a different form of life than the Ancient Greeks there can be no understanding. This claim is consistent with my earlier rejection of the Overlapping Forms of Life Method. The aim of the Overlapping Forms of Life Method is to use the shared portions of a form of life to explain the unshared portions. I claim this is impossible. Here, in contrast, I am claiming merely that when our form of life overlaps with an alien form there can be mutual understanding of the shared portion.

I conclude that SSK studies written to date that claim to convey understanding of alien forms of life cannot actually be doing this. Contrary to the claims of the authors, to the extent that the scientists being studied can be understood, they actually belong to the same form of life as the reader. To make this claim plausible I will briefly show how it can make sense of one of the most famous case-studies that claims to describe an alien form of life, Shapin and Schaffer's Leviathan and the Air-Pump.

Leviathan and the Air-Pump concerns a series of arguments between Thomas Hobbes and Robert Boyle. Boyle believes in vacuums, and in the use of fancy experimental apparatus, and trusts in expertise. Shapin and Schaffer think he is rather like us. Hobbes is very different. He doesn't believe in vacuums, he relies on philosophical argument rather than experimentation, and he distrusts secret groups (including groups of scientists who meet in private). According to Shapin and Schaffer we share a form of life with Boyle, but not with Hobbes. If this is so, and if my claims in this paper are correct, Hobbes should be incomprehensible to the reader, as Leviathan and the Air-Pump is no anthro-novel. Actually, however, Hobbes comes across as being really rather reasonable. How can I cope with this? Have I made a mistake? I claim that I have not, and that our ability to understand Hobbes can be explained in the following way: Shapin and Schaffer are simply wrong to claim that Hobbes' ways of thinking are utterly alien. He shares a form of life with us to some extent, and to that extent he can be understood. For example, Hobbes claims that vacuums cannot exist on a priori grounds. A vacuum would be an "immaterial substance," and "immaterial substance" is an oxymoron. Shapin and Schaffer claim that using such a priori arguments against experimental results is foreign to us. In this, however, they are mistaken. Collins and Pinch's Frames of Meaning, for example, details a number of a priori argu- 
ments that are currently used by conventional scientists against experimental results in parapsychology. While few would accept that Hobbes' argument against vacuums is valid, the forms of reasoning that he employs are still in use today. To some extent at least he is no alien, and to this extent he makes sense to us.

Incidentally, I suggest that Shapin and Schaffer are also wrong in suggesting that Boyle totally shares our form of life. He may believe in vacuums and be fond of experiments, but some of his ways of thinking are very odd indeed. For example, Shapin and Schaffer report that Boyle held that experimental philosophers should seek to produce arguments that will convince men there is a God (1985, p. 319). The idea that it might be possible to produce experimental proof of God's existence is foreign to us, I suggest. I conclude that we can understand both Hobbes and Boyle to an extent, but only to an extent, because their forms of life partially overlap with our own.

I claim that in so far as alien historical actors are alien they cannot be understood because it is impossible to interact with them (apart from the unusual case where remaining documents are sufficient to serve as an anthro-novel). Still, this should not be taken to mean that history is generally impossible. Historians can engage in activities that don't require them to understand historical actors (analyzing economic variables and population trends, for example). More importantly, people from different times and cultures often have quite a lot in common with us, and when forms of life overlap understanding is possible regarding the shared portion.

\section{References}

Barnes, Barnes. 1982. T. S. Kubn and Social Science. London: The Macmillan Press.

Barnes, Barnes and David Bloor. 1982. "Relativism, rationalism and the sociology of knowledge." Pp. 21-47 in Rationality and Relativism. Edited by M. Hollis and S. Lukes. Cambridge, MA: MIT Press.

Bernard, H. Russell. 1988. Research Methods in Cultural Anthropology. Newbury Park, CA: Sage.

Bloor, David. 1983. Wittgenstein: A Social Theory of Knowledge. London: Macmillan.

-Wittgenstein: Rules and Institutions. New York: Routledge.

Bowen, Elenore Smith. 1964. Return to Laughter. New York: Doubleday.

Churchland, Paul. 1988. "Perceptual plasticity and theoretical neutrality: A reply to Jerry Fodor." Philosophy of Science, 55: 167-187.

Collingwood, R. G. (1946) 1961. The Idea of History. Oxford: Oxford University Press. 
Collins, Harry. 1979. "The investigation of frames of meaning in science: Complementarity and compromise." Sociological Review, 27: 703718.

. 1981. "Understanding science." Fundamenta Scientiae, 2: 367380.

. 1983. "An empirical relativist programme in the sociology of scientific knowledge." Pp. 85-113 in Science Observed. Edited by K. Knorr-Cetina and M. Mulkay. London: Sage.

- 1984. "Researching spoonbending: Concepts and practice of participatory fieldwork." Pp. 54-69 in Social Researching: Politics, Problems, Practice. Edited by Colin Bell and Helen Roberts. London: Routledge and Kegan Paul.

. 1985. Changing Order. London: Sage

. 1998. "The meaning of data: Open and closed evidential cultures in the search for gravitational waves." American Journal of Sociology, 104: $293-337$.

Collins, Harry and Martin Kusch. 1998. The Shape of Actions. Cambridge, Massachusetts: MIT Press.

Collins, Harry and Trevor Pinch. 1982. Frames of Meaning. London: Routledge and Kegan Paul.

Davidson, Donald. 1973-4. "On the very idea of a conceptual scheme." Proceedings of the American. Philosophical Association, 47: 5-20.

Feyerabend, Paul. 1987. "Putnam on incommensurability." British Journal for the Philosophy of Science, 38: 75-81.

Finch, Henry A. 1977. Wittgenstein: The Later Philosophy. Atlantic Highlands, N.J.: Humanities Press.

Garver, Newton. 1994. This Complicated Form of Life. Chicago: Open Court.

Glock, Hans-Johan. 1996. A Wittgenstein Dictionary. Oxford: Basil Blackwell.

- 1998. "Forms of life: Back to basics." Paper given at the Joint Session of the Mind and Aristotelian Society.

Heal, Jane. 1998. “Wittgenstein.” Pp. 757-770 in Routledge Encyclopaedia of Philosophy. Edited by E. Craig London: Routledge.

Hollis, Martin. (1967a) 1970. "The limits of irrationality." Pp 214-215 in Rationality. Edited by B. Wilson. Oxford: Basil Blackwell.

—. (1967b) 1970. "Reason and ritual." Pp. 221-239 in Rationality. Edited by B. Wilson. Oxford: Basil Blackwell.

- 1982. "The social destruction of reality." Pp. 67-86 in Rationality and Relativism. Edited by M. Hollis and S. Lukes. Oxford: Basil Blackwell.

1996. Reason in Action. Cambridge: Cambridge University Press. 
Holton, Gerald and Duane Roller. 1958. Foundations of Modern Physical Science. Reading, MA: Addison-Wesley Publishing Company.

Hunter, J. 1968. "'Forms of life' in Wittgenstein's Philosophical Investigations." American Philosophical Quarterly, 5: 233-243.

Jackson, Frank. 1986. "What Mary didn't know." The Journal of Philosophy, LXXXIII: 291-95.

Kindi, Vassiliki. 1995. “Kuhn's The Structure of Scientific Revolutions Revisited." Journal for General Philosophy of Science, 26:75-92.

Kirk, Robert. 1986. Translation Determined. Oxford: Clarendon Press.

Kripke, Saul. 1981. "Wittgenstein on rules and private language," Pp. 238-312 in Perspectives on the Philosophy of Wittgenstein. Edited by I. Block. Oxford: Basil Blackwell.

Kuhn, Thomas S. 1962. The Structure of Scientific Revolutions. Chicago: The University of Chicago Press.

- 1982. "Commensurability, comparability, communicability." Pp. 669-688 in PSA. Vol. 2.

Lenneberg, Eric. 1967. Biological Foundations of Language. New York: John Wiley and Sons.

Lynch, Michael. 1993. Scientific Practice and Ordinary Action. Cambridge: Cambridge University Press.

Nagel, Thomas. 1974. "What is it like to be a bat?." The Philosophical Review, LXXXIII: 435-50.

Popper, Karl. 1959. The Logic of Scientific Discovery. London: Hutchinson.

Quine, W. 1960. Word and Object. Cambridge, Massachusetts: M.I.T. Press.

Sacks, Oliver. 1995. An Anthropologist on Mars. London: Picador.

Shapin, Steven and Simon Schaffer. 1985. Leviathan and the Air-Pump. Princeton: Princeton University Press.

Winch, Peter. (1964) 1970. "Understanding a primitive society." Pp. 78-111 in Rationality. Edited by B. Wilson, Oxford: Basil Blackwell.

Wittgenstein, Ludwig. 1958. Philosophical Investigations, Second Edition. Blackwell: Oxford. 